\section{El discurso apocalíptico y las atribulaciones de su enunciador en la obra de Rubén Darío}

\author{
The apocalyptic discourse and the disturbances of its \\ enunciator in the work of Rubén Darío
}

Ignacio Campos Ruiz Universidad Nacional Autónoma de Nicaragua, Managua ignacampos2003@yahoo.com

(c) UNAN-Managua Recibido: mayo 2017 Aprobado: junio 2017

Apocalipsis de Jesucristo Dios le confió esta revelación para que enseñara a sus servidores lo que va a suceder pronto. Él envió a su ángel para que se lo transmitiera en forma de visiones a su servidor Juan, el cual dice lo que vio, afirmando que ésa es Palabra de Dios y Testimonio solemne de Jesucristo. Feliz el que lea públicamente estas palabras proféticas, y felices quienes las escuchen y hagan caso de este mensaje, pues el tiempo está cerca.

(Juan 1: 1-3)

\section{RESUMEN}

En este trabajo hacemos un recorrido por la obra de Rubén Darío con el interés de examinar cómo el discurso apocalíptico involucra un imaginario que ayuda a sistematizar el planteamiento disconforme del enunciador literario. Asimismo, destacamos que Darío tuvo la capacidad de percibir y plantear de manera crítica distintas problemáticas que hacían peligrar la convivencia colectiva en el momento de la modernidad. Precisamente, se trata de la actitud del poeta de incidir en la sensibilidad humana, como una respuesta a la escisión de la modernidad, a la pérdida de orientación y vacío de Dios.

Palabras clave: Rubén Darío, crítica poética, discurso

\section{SUMMARY}

In this work we take a tour of Rubén Darío's work with the interest of examining how apocalyptic discourse involves an imaginary that helps systematize the nonconforming approach of the literary enunciator. Likewise, we highlight that Darío had the ability to perceive and critically raise different issues that endangered collective coexistence at the time of modernity. Precisely, it is about the poet's attitude of influencing human sensitivity, as a response to the split of modernity, the loss of guidance and emptiness of God.

Keywords: Rubén Darío, poetic criticism, discourse

La obra de Rubén Darío ofrece una percepción apocalíptica de los problemas que arriesgaban la convivencia del ser humano en el contexto de la modernidad. Ante esta amenaza la escritura de Rubén Darío activa un imaginario que actualiza el evento apocalíptico y delata las realidades específicas que generan. En su proceso y recurrencia, este discurso adquiere sentido crítico, tanto por la representación evocativa de fuerzas contrarias localizables en el enunciado, como por la pretensión del texto de contribuir con la modificación de la conciencia de los sujetos. 
Con este discurso de la secularización finisecular del XIX, que hacía notar una ausencia de Dios, Darío pretende incidencias en favor del establecimiento del bien mediante un enunciador poético ${ }^{1}$ que ensaya diversos efectos de sentido en la enunciación.

Ante la escisión espiritual identificada, el autor modernista interioriza la idea del deber ser, proveniente de un pensamiento sincrético, atravesado por lo religioso. Consecuentemente, desde la altura que le permitía la secularización, expresaba: "(...) desde Marco Aurelio hasta Bergson, he saludado con gratitud a los que dan alas, tranquilidad, vuelos apacibles, y enseñan a comprender de mejor manera posible el enigma de nuestra estancia sobre la tierra" (Darío, 1988, p. 102). Con justa razón, la actitud hacia la modernidad y sus efectos fue planteada por los modernistas, desde su forma más inmediata, rica y angustiosa, como lo ha visto Octavio Paz (1991) quien además subrayaba: "instante henchido de presagios, vía de acceso a la gesta del tiempo" (p. 14).

El tema del apocalipsis y su correspondiente imaginario ha adquirido en la literatura hispanoamericana una proyección significativa, con dimensión mítica ${ }^{2}$. En la modernidad tiene que ver con los efectos de la pérdida de la fe, vacío de Dios, entre otras formulaciones, sociológicamente denominada como secularización? Por eso, la incertidumbre y los desmanes del hombre se tornan indicios del apocalipsis en la literatura de Darío, asunto similar plantearían sus congéneres. Gutiérrez Girardot nos aclara la percepción del evento apocalíptico al decir:

No ciertamente en su sentido bíblico de juicio final, sino en sentido intramundano: el juicio final tiene lugar en el mundo y no conduce a un más allá, es un apocalipsis inmanente, sin tribunal y sin juicio. Es el apocalipsis del Yo que es su propio padre y creador y lleva consigo a su propio ángel exterminador (pp. 74-75).

La incursión en los textos de Darío permite visualizar la figuración apocalíptica desde el tamiz del enunciador, pues este funciona como constructo. Ese yo es un enunciador que se va conformando como sujeto textual, con variaciones siempre ficcionales dentro del texto. De acuerdo con Blanco (2004) "El que habla es siempre un 'yo', y lo hace siempre 'aquí' y 'ahora'. [...] El enunciador no tiene rostro, no se puede 'ver' ni 'oír', ni 'tocar'. El enunciador es siempre implícito" (p. 12), asimismo, apoyado en Benveniste, Blanco (2004) plantea que el enunciador es una instancia, y "Esa instancia designa el conjunto de operadores y de parámetros que controlan el discurso".

1 Empleamos la sinonimia de enunciador, correspondiente a hablante, voz y yo lírico.

2 Así lo ha hecho notar Geneviéve Fabry, al considerar que "El mito del Apocalipsis, en las variantes más fieles, remite a la revelación profética de un acontecimiento dramático para la humanidad, en el que las fuerzas del mal vencen a las del bien en un gran cataclismo cósmico, después del cual Dios destruye los poderes dominantes para instaurar la supremacía del bien alcanzándose así el fin de los tiempos" (Fabry, 2012: 2).

3 Gutiérrez Girardot hacía notar que esta secularización "no solo consistió en el uso de nociones y conceptos religiosos para expresar cosas mundanas y profanas, no sólo, pues, en la 'mundanización' de la vida, sino en algo más profundo que anunciaron Hegel y Jean Paul Sartre y desde Nietzsche se conoce como 'la muerte de Dios'" (Gutiérrez Girardot, 2004, pp. 82-83). 
Agrega que "como el primer acto del lenguaje consiste en 'hacer presente' alguna cosa, no se puede concebir más que en relación con un cuerpo susceptible de sentir esa presencia" ( $p$. 13). En el caso que nos ocupa, la imagen del "yo", aunque pueda coincidir con la figura autoral real, será siempre una imagen simbólica, textual, que se siente comprometida a advertir un evento trascendente, una conmoción mundial. En consecuencia, el enunciador modernista refiere el evento apocalíptico en el sentido en que lo haría un integrante de una iglesia que cumple con el mandato de predicar la palabra sagrada ante determinada situación. El discurso dariano en esta condición, articula aquello que comúnmente se veía instaurado en otros ámbitos de la vida social y cultural.

Para su efecto comunicativo, los enunciados apocalípticos asumirán distintas modulaciones del enunciador o hablante poético, que entonan, según el caso, la manera de captar y provocar sentido en la lectura. A modo de dispositivo, estos enunciados y voces reaccionan en función correctiva o, bien, conclusiva. Para crear las evocaciones del pasaje apocalíptico, con su ambiente y efecto de cataclismo, el enunciado integra el imaginario y las emotividades elevadas (pathos) que cree necesario.

La lectura de este sujeto poético modernista comúnmente lo hemos relacionado con la prolongación de la figura autobiográfica; sin embargo, ahora experimenta variantes asociadas con las posibilidades dialógicas entre la instancia real autobiográfica, la realidad externa y la instancia del hablante poético. Las voces pretenden condenar o redimir, configurando una identidad de quien advierte, predica el bien y la verdad. Un caso así presenta el primer poema de Cantos de vida y esperanza, donde el hablante poético o enunciador acentúa la versión de la interioridad individual de imprimir orientación, fe y verdad a sus palabras $\mathbf{4}$, perspectiva que lo induce a emitir predicciones.

Asociado a lo apocalíptico está la noción de imaginario, en el sentido en que lo concibe Néstor García Canclini, en entrevista realizada por Alicia Lindón:

(...) lo imaginario remite a un campo de imágenes diferenciadas de lo empíricamente observable. Los imaginarios corresponden a imágenes simbólicas de lo que observamos o de lo que nos atemoriza o desearíamos que existiera. (...). Lo imaginario viene a complementar, a dar un suplemento, a ocupar las fracturas o los huecos de lo que sí podemos conocer. (...) (En Lindón, 2007: 90)

De igual modo, es crucial destacar que la revelación de lo imaginario y sus indicios operan como imaginación activa, que va a estar influenciada por la experiencia originaria y universal, en cuanto a que la vida simbólica y cultural, según Ross (1992, p. 326), va a quedar investida de una especie de imagen-de- sentido. Chevalier (2003, p. 110) hacía notar que en el apocalipsis todo o casi todo adquiere valor simbólico, ya sean cifras, cosas, partes del cuerpo, personajes en escenas, colores, visiones, todo lo cual requiere una interpretación.

La lectura de los textos y fragmentos del discurso apocalíptico de Darío, por tanto, van a revelar los síntomas de una crisis, como una postura sensible del autor ante la vida, en tanto el enunciador unas veces muestra incertidumbre y, otras, determinaciones.

4 Al respecto decía: "Vida, luz y verdad, tal triple llama/ produce la interior llama infinita; / el Arte puro como Cristo exclama: / Ego sum lux et veritas et vita!", 
Prematuramente, en Epístolas y poemas (1885) el hablante poético lamenta el acabose de lo moral, ya sea por lo que atenta contra la fe religiosa o, en términos generales, por aquello que genera incertidumbre en su conciencia de poeta en ciernes, creyéndose intermediario entre los hombres y la divinidad para encaminar a los demás. El enunciador aludía tanto a la función de la poesía, como al riesgo del vacío de fe y, por lo tanto, de la presencia del mal.

En la epístola "Erasmo a Publio" el autor delega el discurso moralizante a un consejero para que proyecte la imagen de un Dios castigador del ser humano que se deja llevar por las pasiones y vanidades del mundo. La estructura es similar a decir "yo -enunciador- presento a Erasmo y a Publio, de ahí Erasmo que se encargue de seguir la enunciación": Aquí el yo (Erasmo) frente al tú (Publio) se ha convertido en un "nosotros" ("nosotros del ideal mantenedores"), donde no hay participación activa del aconsejado. Quien introduce el discurso presenta a Erasmo, como "Discreto Erasmo ya de luengos días" y a Publio como "joven", "cariñoso y dulce". Es decir, la relación entre la vejez (sabiduría) y la juventud (inexperta) se establece en un orden jerarquizado.

Se trata de Erasmo (enunciador) aconsejando a Publio (enunciatario) a pensar y a actuar por el camino del bien y buscar la felicidad, evitando la adulación y la humillación. Basta acudir a la parte inicial de esta epístola para percibir las implicaciones de sentido de semas y expresiones del hablante poético grandilocuente que configura el mensaje: "perdición", "terribles penas", "soberbia infausta", "destronca", "huracán siniestro", "placeres tentadores", "crespa orgía", "meretriz locuaz", "torpe bacanal", "olvidada de Dios", "trueno predicador de maldiciones rudas", "hoguera de increada luz", "tremendo", "fulminante" y "castigo". Estas palabras y estructuras adquieren vínculo con la imagen del evento apocalíptico, más cuando literalmente esta voz enuncia que la sociedad se ríe olvidada de Dios, de lo infinito/ y de la eternidad... ;No; que hay un trueno/ predicador de maldiciones rudas. Aquí la serie se opone a "arcángel puro", "paraíso", "Dios", conformando así un espectro isotópico de mal, vs. el bien. Estos semas y estructuras están contagiados de abstracciones emitidas por un hablante envalentonado en las reminiscencias de la literatura clásica, no obstante, su disconformidad y escenificación han quedado planteadas.

En el poema "El porvenir" concurren los estadios del tiempo de la sociedad humana expuesta a un enjuiciamiento divino: El Ángel del Señor a juicio llama. Aquí la imagen de Dios se presenta en su dimensión conmovedora del clisé retórico: Vago rumor se oyó por el abismo, / rumor de cataclismo; / hondo estremecimiento/ anuncio de gigante movimiento, que en relación con el tiempo del presente imaginado aparece escindido entre el escepticismo y los alcances del progreso y la ciencia. Sin embargo, el futuro no necesariamente será de castigo sino de restauración.

En el cuento El rey burgués quien suministra la información del estado calamitoso del artista es el personaje que hace de poeta, que cree tener méritos al esperar con expectativas la redención, como lo muestra su actitud comprometida:

¡He querido ser pujante! Porque viene el tiempo de las grandes revoluciones, con un Mecías todo luz, todo agitación y potencia, y es preciso recibir su espíritu con el poema que sea arco triunfal, de estrofas de acero, de estrofas de oro, de estrofas de amor. 
Irónicamente, el personaje del cuento que dice apertrecharse de una poesía según la expectativa de la empresa redentora aparecería más bien como "el infeliz", "un pobre diablo" condenado a muerte por efectos de la injusticia terrenal. En esta ocasión de "la noche sombría" "en el palacio había festín", derroche de opulencia, placer y brindis, es decir, se celebraba el triunfo del mal sobre el bien. En este tipo de discurso la imagen del gran vacío permite a las voces expresar de cierto modo, el grado de conciencia por participar en la armonía del mundo.

En el cuento ¿Por qué? el enunciador (narrador) alude a la manera en que la sociedad se ha deshumanizado y ha echado los diversos valores éticos y morales por la borda. El narrador disconforme y marginal es Juan Lanas y se dirige a Dios como narratario (-¡Oh, Señor!, el mundo anda muy mal (...) para pedirle pronta justicia. Este narrador realiza un inventario de situaciones y actos que pone en entredicho los ámbitos sociales, políticos, religiosos, administrativos, morales, entre otros, de un mundo que se resquebraja. El factor de disconformidad conduce al narrador a imprimirle un tono increpante y emotivo a su discurso, y de este modo acentúa la visión escatológica de carácter cronológico, es decir, de aquello que está por suceder (El siglo que viene verá la mayor de las revoluciones que han ensangrentado la tierra-dice). Se trata, por tanto, de un enunciador (narrador-personaje) que asume la actitud de un líder social inspirado en el discurso y tono apocalípticos:

Pero los anuncios del cataclismo están ya a la vista de la humanidad y la humanidad no los ve; lo que verá bien será el espanto y el horror del día de la ira. No habrá fuerza que pueda contener el torrente de la fatal venganza. Habrá que cantar una nueva marsellesa que como los clarines de Jericó destruya la morada de los infames. El incendio alumbrará las ruinas. El cuchillo popular cortará cuellos y vientre odiados; las mujeres del populacho arrancarán a puños los cabellos rubios de las vírgenes orgullosas; la pata del hombre descalzo manchará la alfombra del opulento; se romperán las estatuas de los bandidos que oprimieron a los humildes; y el cielo verá con temerosa alegría, entre el estruendo de la catástrofe redentora, el castigo de los altivos malhechores, la venganza suprema y terrible de la miseria borracha

En "Salutación del optimista" de Cantos de vida y esperanza lo apocalíptico se compenetra de la situación depresiva dejada por las pérdidas de las colonias de España en América, en tanto emerge la voz de la autoconciencia del enunciador fraterno y augural, que pretende armonizar el estado emocional y de fe mediante los "nuevos himnos" para incidir en el cambio. Es decir, advierte de la presencia de Dios para comenzar nuevos tiempos. Las imágenes apocalípticas, tanto mesiánicas como fatales, van surgiendo como contrapuntos entre el presente y el futuro esperanzador, a fin de sobreponerse a las heridas dejadas por la fragmentación de la hispanidad. De este modo, el texto alegoriza tanto el mal como el bien: Retrocede el olvido, retrocede engañada la muerte; / se anuncia un reino nuevo, feliz sibila sueña. Es notoria, además, la actitud imperativa de esta voz al elevar su tono, mediante el cual usurpa la instancia de autoridad: Abominad la boca que predice desgracias eternas, / abominad los ojos que ven sólo zodíacos funestos, / abominad las manos que apedrean las ruinas ilustres / o que la tea empuñan o la daga suicida. Estos versos que en un primer nivel de lectura alientan para abandonar lo dañino, aquello que puedan decir los falsos profetas, son opuestos al espíritu de fe y esperanza. Son estructuras poéticas que se compenetran del imaginario apocalíptico desde otro nivel especulativo: boca (símbolo de profecía), ojos (percepción de la sabiduría), manos (símbolo de poder), tea (equivalente a fuego, asociado a la presencia de Dios), daga (equivalente a la espada, simbolizando así la justicia).

5 Veamos al respecto este fragmento: "El Ángel del Señor a Juicio llama/ al Pasado, al Presente/ y al Porvenir. El eco se derrama, / y el abismo se inflama/ al tronar la palabra omnipotente". 
La percepción de pérdida o fragmentación de la hispanidad, no obstante, induce al enunciador a expresar las razones por las cuales se pronuncia, haciéndolo de forma impersonal, como pretendiendo objetividad, mediante imágenes impactantes de una fuerza sobrenatural que mimetiza el evento catastrófico:

Siéntense sordos impetus en las entrañas del mundo,

la inminencia de algo fatal hoy conmueve la Tierra;

fuertes colosos caen, se desbandan bicéfalas águilas,

$y$ algo se inicia como vasto social cataclismo

sobre la faz del orbe (...)

La conciencia del enunciador queda registrada también a modo de incidencia en los demás, con la esperanza de que Dios venga a reinar en quienes lo escuchan, pues traerá cambios radicales, como refiriendo la fundación de la Nueva Jerusalén:

La latina estirpe verá la gran alba futura, en un trueno de música gloriosa, millones de labios saludarán la espléndida luz que vendrá de Oriente, Oriente augusto en donde todo lo cambia y renueva Y asi sea Esperanza la visión permanente en nosotros, ¡Ínclitas razas ubérrimas, sangre de Hispania fecunda!

Se trata de que el hablante poético pluraliza su experiencia personal del yo al referir "la visión permanente en nosotros". En cambio, en el poema "Cantos de esperanza", el hablante se hace eco de los acontecimientos bélicos y sus efectos de la guerra ruso-japonesa acaecida entre 1904 y 1905 . En correspondencia con este hecho histórico el texto introduce en su estrofa inicial el evento que justifica el motivo apocalíptico acudiendo al recurso de la alegoría de la muerte, mediante estructuras como "gran vuelo de cuervos", "mancha", "amagos de peste", "asesinan". Sumada a esta alegoría está la interrogante retórica que introduce en el poema el síntoma de la presencia del mal en la tierra o, dicho de otra manera, la secularización queda expresada en la desorientación religiosa, que el hablante poético percibe desde su atalaya espiritual: ¿Ha nacido el apocalíptico Anticristo?

De la estrategia retórica el enunciador va a pasar a la forma impersonal e imaginada por el cuerpo social (Se han sabido presagios y prodigios se han visto), para después convertir esta versión en una formulación que se va a plegar a la individual del hablante, obteniendo así una primera conclusión: Y parece inminente el retorno del Cristo. Esta voz intermediaria luego apostrofa y se pronuncia a favor de la redención urgente ante el enunciatario: ¡Oh, Señor Jesucristo! por qué tardas, qué esperas/ para tender tu mano de luz sobre las fieras/ y hacer brillar al sol tus divinas banderas! Se trata de la restauración profunda, no en términos de la violencia trágica sino del cambio hondamente espiritual y pacificador:

Ven, Señor, para hacer la gloria de ti mismo

ven con temblor de estrellas y horror de cataclismo,

ven a traer amor y paz sobre el abismo.

El enunciador, en su estilo reiterativo, adquiere un nuevo estatus al contribuir a subsanar ese vacío espiritual, pues al dirigirse al enunciatario (Jesucristo), al final se le presenta como una ofrenda. Este hablante se convertirá en incensario, es decir, medio o instrumento de purificación, a modo de ángel o sacerdote ante el trono de Dios: 
Y tu caballo blanco, que miró el visionario, pase. Y suene el divino clarín extraordinario. Mi corazón será brasa de tu incensario.

En el poema "Mientras tenéis, joh negros corazones!" se nota el enfrentamiento entre fuerzas contrarias manifiestas entre el vulgo hostil y los artistas incomprendidos. De ahí que cuando el enunciador asocia la imagen de Cristo a la figura del "pensador" y "divino" construye la relación solidaria con los artistas, a costa de la sacralización en los siguientes términos: Pero tu carne es pan y tu sangre es vino, refiriéndose a "Shakespeare pobre" y a "Cervantes manco". Este enunciador, además, va a mostrar una tonalidad de advertencia al percibir las injusticias con los artistas:

Un gran Apocalipsis horas futuras llena

¡Ya surgirá vuestro Pegaso blanco!

Se trata no sólo de que la literatura asuma un discurso de la representación del apocalipsis como manifestación disconforme de un tiempo presente, sino también de una justicia en términos de la recepción artística, ya que el "Pegaso blanco" está inmerso en un sentido de ironía, que advierte una deuda simbólica.

En "Letanía a nuestro señor Don Quijote" el hablante se dirige a este personaje para que escuche los ruegos de intercesión por "nosotros", por estar con el alma a tientas, con la fe perdida, / llenos de congojas y faltos de sol. De esta modo, la letanía que conmemora el III centenario de El Quijote de Cervantes, al sacralizar al personaje y mundanizar lo sagrado, deja al hablante relativamente distanciado de Dios, y su vínculo no es directo, sino que necesita de un mediador o intercesor: Ruega generoso, piadoso, orgulloso; / ruega casto, puro, celeste, animoso; / por nos intercede, suplica por nos, / pues casi ya estamos sin savia, sin brote, / sin alma, sin vida, sin luz, sin Quijote, / sin pies y sin alas, sin Sancho y sin Dios. Esta inversión la había hecho notar Pedro Salinas, al advertir que la letanía es "una canonización poética de un nuevo santo hispánico. Santo patrono del idealismo y la heroicidad moral" (Citado por Ruiz Barrionuevo, 2002, p. 110).

El poema "A Colón" de El canto errante, desarrolla el tema de la falta de trascendencia o fracaso de las repúblicas del continente americano, en su condición degradada (por guerras, transculturación y otras formas de violencia), dejando la impresión de lucha entre Caínes y Abeles; esta percepción se acentúa con la versión del enunciador colonizado: Un desastroso espíritu posee tu tierra / donde la tribu unida blandió sus mazas, / hoy se enciende entre hermanos perpetua guerra / se hieren y destrozan las mismas razas. En la lectura del poema nos encontramos con que el tono del hablante poético, que al inicio le había gritado ¡Desgraciado Almirante después aparece solicitando a este personaje histórico ya rebajado de su heroísmo ("pobre Almirante"), que interceda por la "América histérica" para no merecer el castigo divino:

Duelos, espantos, guerras, fiebre constante en nuestra senda ha puesto la suerte triste: ¡Cristóforo Colombo, pobre Almirante, ruega a Dios por el mundo que descubriste! 
Este enunciador individual luego se pluraliza, al referir La cruz que nos llevaste padece mengua, asimismo contribuyen a la pluralización las referencias a América como colectividad. En cambio, en el cierre del poema "Momotombo" la figura de Cristóforo Colombo se presenta emparejada con la de Víctor Hugo y del volcán Momotombo. Ambos están concebidos como montañas habitadas por el fuego de Dios, porque uno de ellos escuchó el rugido del coloso y el otro lo cantó, desplazando de esta manera el sentido de majestuosidad y grandeza del volcán hacia la imagen de ambos personajes. Y aunque el discurso cuestiona que se haya olvidado la trascendencia del hombre y su cultura, la instancia del yo se dirige únicamente al tú (Momotombo). En estos pasajes del poema es notorio el recurso del pathos apocalíptico, pues la emotividad del enunciado contribuye a destacar el acercamiento crítico de la lucha de fuerzas contrarias:

¡Hacia el misterio caen poetas y montañas

y romperás el cielo de cristal

cuando luchen sonando de Pan las siete cañas

y la trompeta del Juicio Final!

Este nuevo elemento simbólico (el dios Pan) es la figura mitológica y mundana de grandes pasiones que hacía sonar agradables entonaciones con su flauta de siete cañas, dando la impresión de siete cielos y, según el sentido del texto, se enfrenta ante la justicia final. La relación con el texto bíblico es que Los siete ángeles de las siete trompetas se prepararon para tocar, y después de cada sonada emergía una acción o sucesos que afectaban al ser humano.

En "Salutación al Águila" el tema plantea la aceptación de la presencia de Estados Unidos, simbolizado en el Águila, sólo con la condición de que sea en son de paz y de influencia en el progreso de los países de América Hispana. Hay en el texto un simbolismo mítico-religioso, asumiendo que en el cristianismo el águila es símbolo del mensajero celestial y de resurrección. Por otra parte, el águila jupiteriana es la tempestad teriomórfica, que sustituye con animales el protagonismo de las historias narradas. En ese sentido leamos la estrofa:

Por algo eres la antigua mensajera jupiteriana

por algo has presenciado cataclismos y luchas de razas,

por algo estás presente en los sueños del

por algo eres el ave que han buscado los fuertes imperios.

En el poema "A un pintor" de la serie "Lira alerta" de El canto errante el hablante poético dice al "Pintor de melancolías" "deja esa visión" pues "Hay soles de eternos días", acudiendo así a la imagen del sol como figura que simboliza inmortalidad e inteligencia cósmica. Este hablante lírico, que alienta al pintor a vivir el momento, ha percibido previamente las imágenes del pintor como señales apocalípticas: Hondas negruras de abismo/ y espanto fatal, / lividez de cataclismo/ o anuncio mortal. En la siguiente estrofa el hablante interioriza tanto las señales que hasta se siente amedrentado: Ráfagas de sombra y frío/ y un errante ir... / ( $V a$ Vomos a morir, Dios mío, / vamos a morir!

En el poema "Agencia" de El canto errante el enunciador lírico reacentúa el discurso del profeta Malaquías cuando se refiere a ciertas señales apocalípticas: ${ }^{6}$

París se flagela de placer.

Un cometa va a aparecer.

Se cumplen ya las profecías

Del viejo monje Malaquías. 
Después de expresar indicios de que todo va mal en distintas partes del mundo, el hablante refiere cómo se han ido desvirtuando los valores, incluso da muestras de este deterioro mediante distintos factores: la pederastia, la pérdida de fe, la cuestión del poder político y religioso, el orden moral y el imaginario colectivo: ${ }^{7}$

Se organizará por un bill
la prostitución infantil.
La fe blanca se desvirtúa
y todo negro continúa.
En alguna parte está
el palacio del Anticristo.
Se cambian comunicaciones
entre lesbianas y gitones.
Se anuncia que viene el Judio
errante... ¿Hay algo más Dios mío?...

En este poema el enunciador individual a modo de lamento, se dirige al enunciatario aludido en el último verso. En el poema "Santa Elena de Montenegro" de la sección "Varia" del Poema del otoño y otros poemas encontramos al enunciador con una percepción social y religiosa, que asocia reminiscencias de terror, hambre y desamparo como si se tratara de la vida en plena Edad Media. De esta impresión emerge el discurso apocalíptico. En primer plano, surge la situación de emergencia que vive un conglomerado de personas afectadas por un fuerte terremoto, y que a modo de convulsión cósmica, es testimoniada así: Pasan furias haciendo gestos, / pasan mil rostros descompuestos. ${ }^{8}$. Pero este testimonio va a corresponder a la instancia de alguien capaz de percibir las señales: allá arriba hay signos funestos. De esta manera el enunciador considera imperativa la justicia: Falta la terrible trompeta dirá. Incluso, este hablante interioriza en mayor grado el evento (Mas oye el alma del poeta/ crujir los huesos del planeta), semejante al juicio final (Van rebaños dolientes... van/visiones de duelo y afán/ cual vio en su apocalipsis Juan).

Se cumple, por tanto, la analogía entre el enunciador poético (profeta) y el evento terráqueo (la conciencia humana).

En el poema "¡Pax!" de la "Selección de textos dispersos" de Poesías, leído por Darío en su proyecto pacificador al pasar por Estados Unidos en 1915, escribe acerca de que el mal social y político, las guerras injustas y el progreso (aplicado incorrectamente), tendrán su momento crítico, situación que, no obstante, será para la restauración, según el enunciador atribulado:

6 Se refiere a las profecías atribuidas al arzobispo San Malaquías de Armagh (10941148) pero fueron publicadas siglos después (1595 y 1690), cuando los eventos ya habían sucedido.

7 La alusión al Judío Errante en los últimos dos versos del poema, proviene del imaginario colectivo que origina esta leyenda o texto cultural, pero que tiene su origen en un pasaje bíblico cuando el personaje ofendió a Cristo camino a su crucifixión. 8 La cifra "mil", que en lenguaje bíblico significa muchedumbre, es muchedumbre sufriente, inmersa en un dramatismo singular. 


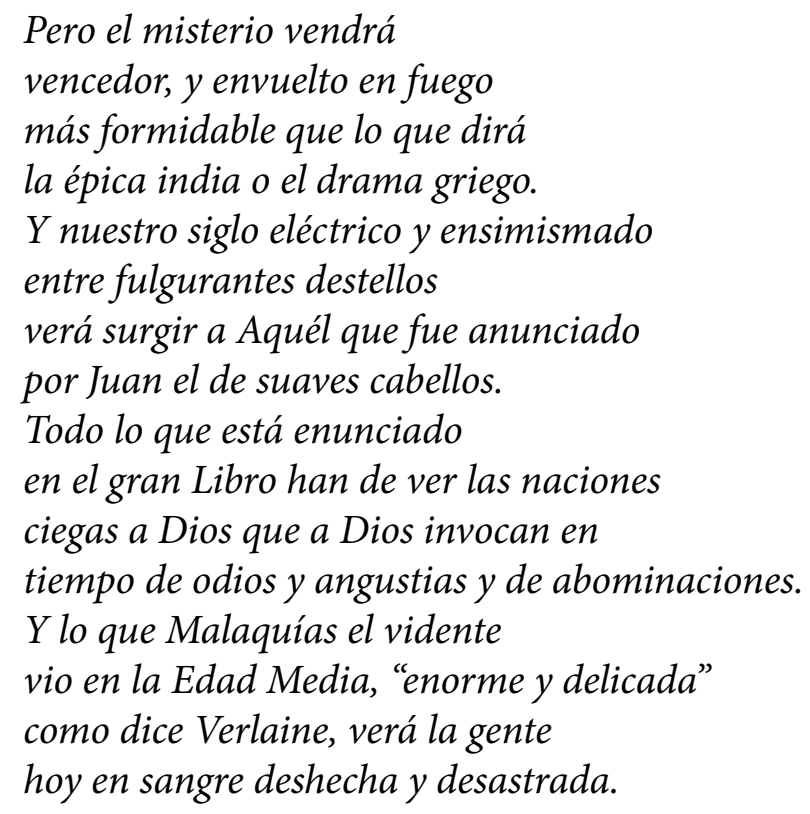

En este fragmento, saturado de elementos simbólicos, el evento concreto, presumiblemente nunca registrado por la historia ni la cultura, se presenta dimensionado. Pero esta imagen de convulsión cósmica no será otra que la del "siglo eléctrico". Es decir, el de la modernidad industrial y capitalista, que ha hecho méritos para presenciar y ser parte misma del apocalipsis. Aquí los indicios corresponden tanto a la paz, como a la fe y a la justicia. En consecuencia, el hablante poético dirá que (....) Jesucristo no está muerto/ y contra el homicidio, el odio, el robo/ Él es la Luz, el Camino y la Vida. En este texto el enunciador iterativo acude a la imagen apocalíptica para persuadir al hombre acerca de su conducta, que de no modificarla le caerá la maldición::

Si la paz no es posible, que como en Isaías

las ciudades revienten.

Que sean de tinieblas las noches y los días;

que las almas que sienten

soplo de Dios, duerman sueño profundo

mientras que se desangra y se deshace el mundo.

Y que cuando del apocalíptico enigma

surja el caballo blanco, con resplandor y estigma,

los únicos que se hundan en la santa Verdad

sean los puros hombres de buena voluntad

que entre las zarzas ásperas de este vivir han visto

las huellas de los pasos de Nuestro Padre Cristo. 


\section{CONCLUSIONES}

Hemos expuesto hasta aquí cómo Rubén Darío formula la visión que tiene sobre los problemas mundiales, continentales o simplemente humanos, acudiendo a un enunciador poético que se ve atribulado ante el imperativo de revelar tales imágenes. Este enunciador, depositario de la conciencia crítica, logra un estatus de comunicación con Dios; como tendencia del discurso poético se presenta ante el enunciatario bíblico (Jesucristo o Dios), otras veces es ante la figura colectiva (América Latina o América Hispana) y en menor frecuencia ante figuras de la historia y la cultura. Su pretensión es enunciar la necesidad de una toma de conciencia de la crisis que atraviesa la sociedad del momento, en situaciones específicas.

El empeño de Rubén Darío por la actualización del discurso apocalíptico lo lleva a proponer variantes del enunciador literario, sean estas jerárquicas o de acentuación emotiva, ideológica e hispanista. Esta aplicación paradigmática del discurso bíblico, asimismo, funciona no sólo como estrategia del autor por enriquecer las distintas posibilidades semánticas y expresivas de la interioridad del texto, sino también como una exteriorización de la angustia colectiva y personal, y la necesidad de confiar en Dios y en la historia. Entre tanto, el corpus de fragmentos en que se ha basado este trabajo, queda como una macroestructura en la que se desarrolla el tema axiológico de una nueva sociedad con valores constructivos. 
Blanco, D. (2004). Autor, enunciador, narrador. En Lienzo, Revista de la Universidad de Lima, $N^{\circ} 25,9-26$.

Chevalier, J. (1986). Diccionario de los símbolos. Barcelona: Herder

Cirlot, J. E. (2006). Diccionario de símbolos. Madrid: Ediciones Siruela.

Darío, R. (1988). Historia de mis libros. Managua: Nueva Nicaragua.

Darío, R. (1989). Poesía. Ciudad de la Habana: Editorial Arte y Literatura.

Darío, R. (1994). Cuentos completos. Managua: Nueva Nicaragua.

Fabry, G. (2012). "El imaginario apocalíptico en la literatura hispanoamericana: esbozo de una tipología. En Cuadernos Líricos. $N^{\circ} 7$. Versión electrónica consultada en febrero de 2015 en http://lirico.revues.org/689

Frye, N. (1988). El Gran Código. Una lectura mitológica y literaria de la Biblia. Barcelona: Gedisa.

Gutiérrez, G. R. (2004). Supuestos históricos y culturales. Bogotá: Fondo de Cultura Económica.

Lindón, A. (2007). Diálogo con Néstor García Canclini. ¿Qué son los imaginarios y cómo actúan en la ciudad? (Entrevista). En Revista Eure Vol. XXXIII, Nº 99 (89-99). Versión electrónica. Extraído el 16-2-2016 en http://www.scielo.cl/pdf/eure/v33n99/art08.pdf

Pastor García, R. (1996). Lo que está a punto de suceder. Introducción al Apocalipsis. salamanca: Estudio Teológico de San Ildefonso.

Paz, O. (1991). Cuadrivio. Barcelona: Biblioteca de bolsillo.

Ros, W. (1992). Nuestro imaginario cultural. Simbólica literaria hispanoamericana. Barcelona: Anthropos.

Ruiz Barrionuevo, C. (2002). Rubén Darío. Madrid: Síntesis. 